\title{
Academic research libraries in
}

\section{Germany}

\author{
By Elma Mittler
}

Director of the University Library

Heidelberg, Federal Republic of Germany

\section{The Heidelberg experience: A century of collaboration.}

\section{Heidelberg 1888: Isolation}

Karl Zangemeister became university librarian in 1873, the first professional librarian in Heidelberg. Within several years, he restructured the library's collection, refining the divisions established by his predecessors. Nevertheless, individual shelf numbers were rare. Groups of books by one particular author, or about a specific topic, had the same shelf number, a disadvantage even today. He developed a unique system, however-not comparable to any other in Germany. Such individualism is common in German libraries. Zangemeister also extended the library operating hours, resulting in tripling the use of the reading room within twoyears and doubling the number of book loans.

Apart from the systematic catalog and shelf order, the library building bears the strongest marks of Zangemeister's work. The state architect of Baden, Durm, built it as a "castle of science," around the Manesse manuscript. The Codex Manesse is the most valuable manuscript in Germany, with more than 5,000 verses of Minnesingers (troubadours of the Middle Ages) and-even more importantly-with 139 full-page portraits of poets. It was lost in the Thirty Year's War, and when returned from Paris in 1888 it turned the University of Heidelberg Library into a national sanctuary. This, and only this, explains the construction of the magnificent castle building, featuring modular, steel-concrete bookstacks.
It is notable that Zangemeister's seven-page, handwritten paper of November 4, 1897, has become a classic text for library architecture. A section under "General Needs" demanded central heating: "In the book stacks, a temperature of ten degrees Celsius, forty-nine Fahrenheit, is sufficient in winter. This was the decision by the Academic Senate of the University." Obviously the University wanted to save energy and did not intend to open up the stacks to readers" intensive use.

Unlike libraries in the United States, where open access is the norm, German libraries feature closed stacks. The seemingly great service of having a book brought to the reader's desk, in fact, involves troublesome work for the reader at the catalog and in ordering the books.

It is interesting to note that, at the same time as the first professional librarian was hired, an extensive expansion of the departmental libraries began in Heidelberg. Nobody knows if this expansion could have been avoided with a different library philosophy toward a central library.

The expansion of the institute was linked with an increasing tendency toward scientific specialization. Research and teaching depended more and more upon the existence of German institutes with departmental libraries. Due to the competition between German universities and university administrations, the Baden government was forced to provide the necessary means to support departmental libraries in order to obtain, or even keep, professors. The faculties, therefore, built their own 
book collections and the main library became more and more isolated. This is evident in budget cuts to the University Library by the Ministry of Education. Nevertheless, Zangemeister and his successor, Wille, managed to increase the library budget to the considerable sum of $60,000 \mathrm{RM}$, which only Leipzig University Library could match at the time. Although this position could not be maintained forever, it lasted into the 1930s. Heidelberg remained one of the top university libraries in Germany-a library in splendid isolation.

\section{Heidelberg 1930s-1940s: Frustration}

Twenty years after its construction in 1888 , the library building was supposed to be expanded, according to architect Durm's plans; yet in 1925, no one remembered this. The only building built by the University was the "New University," also called the "White House." The American ambassador to Germany, Schurman, raised funds in the United States for its construction in 1928. In the main library, on the other hand, other worries were more pressing during these years. Only with the greatest difficulty could foreign literature be acquired. In order to ensure that at least one copy of the most important foreign publications was held in Germany, a system of shared acquisition was started, called the "Special Subjects Collection Plan." Heidelberg, even then, had a specific obligation to collect books on art history, archeology, and egyptology.

In this shared acquisition system, Heidelberg University Library had a recognized position. This can still be detected in the library hierarchy established by the interlibrary loan office in Berlin in 1928. First came the Prussian Libraries, followed by the County Library of Saxony in Dresden, and the University Library of Leipzig, immediately followed by Heidelberg. On the other hand, the names of the other libraries of the State of Baden came up considerably later.

As a consequence of the shared acquisition system, an attempt was made to create a printed German Union Catalog. The Union Catalog of Prussian Libraries, a card catalog, served as a basis. In Nazi Germany, all librarians had to introduce unified cataloging rules in 1936. Those rules consisted of the Prussian cataloging rules established by librarians who were classicists in Breslau and in Berlin about 1900. They organized the titles according to grammatical order rather than givenword order."The Great Book of Librarianship," for example, will be found in a German catalog under "book," not under "great."

The proof sheets for bibliographic description, printed according to the Prussian Union Catalog, were sent from one German library to the next. Every library entered additional titles.
After the second World War, the endeavor was not continued. The records were lost, and onethird of the content of German libraries was destroyed during the war. Not surprisingly, a German Union Catalog has not been established until now. German librarians had been discouraged to start a modern, national union catalog.

\section{Heidelberg 1988: Challenge}

Fortunately, Heidelberg was spared from war destruction because the Americans had decided to establish their headquarters there. The table that General Eisenhower used in his office as Commander-in-Chief of the American Army continues to be a tourist attraction. The Heidelberg University Library was used for the preparation of the Nuremberg trials against the Nazi leaders and was, hence, emptied out completely. Several American soldiers removed printed books, or even manuscripts. Sometimes such items are returned: for example, in 1987 a medieval manuscript of the "Minneburg," the castle of love, was returned by an American.

In the 1950 s, the library building seemed functional, even though it was already far too small. Whereas other cities, destroyed by the war, built one new university library building after another, in Heidelberg nothing ever passed the planning stage.

Only a branch library for the sciences on the new campus in the "Neuenheimer Feld" opened in 1978 , but this library also had to serve as a storage library for the humanities so that the main building could be renovated. I was able to use this situation as an opportunity to introduce some of the functions of a modern library building into the old walls of the main library building. The former closed stacks were changed into open-access stacks and reading areas. Because of limited space, however, the accession order in Germany, called "Numerus currens" had to be maintained. All books bought in the last twenty years were brought into the openaccess areas. For subject access, users must use the systematic catalog. Books and readers are no longer isolated; they are now brought together.

An information center for the catalogs of the library was created. This includes the Union Catalog of the complete holdings of more than 100 departmental libraries and about 20 other libraries in Heidelberg, including the public library. In this way, the libraries are working together. In order to store the older book collection in the city center again, underground stacks are being constructed. These will be connected to the library by an automatic transport system. We hope that patrons will be served better so they will no longer have to wait more than two days for books ordered from the Neuenheimer Feld. These days, more than 600,000 books a year are transported between the 


\section{FOOD FOR THOLGGHT}

For a taste of what's cooking in sociology, applied social sciences, and linguistics, dip into sociological abstracts (sa), Social Planning/Policy \& Development Abstracts (SOPODA) or Linguistics and Language Behavior Abstracts (LLBA).

sa, ŚOPODÁ, and LLEÁA transcend linguistic boundaries to bring you in-depth abstracts from 1,800 core and ancillary journa's published worldwide.

sa and SOPODA are available in three eminently palatable formats: online from BRS, Dialog, Data-Star, and DIMDI; in print; and now, together for the first time, on the sociofile compact disc.

LLBA can be accessed online via $B R S$ and Dialog, and appears in print quarterly.

A variety of user aids including user's manuals and the sa Thesaurus of Sociological Indexing Terms (2nd Edition, 1989) will add special flavor to your searches.

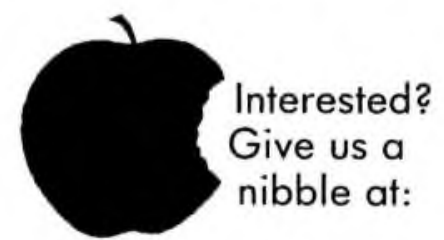

sociological abstracts, inc.

P.O. Box 22206

San Diego, CA 92122-0206

(619) $695-8803$

FAX: (619) 695-0416 main and the branch libraries.

The division of the library into a branch library for sciences and medicine, and into a main library for the humanities, made automation a necessity. Since 1978 Heidelberg has used a system called Dobis-Heidi, first for circulating and now also for cataloging. Since 1983 the library has a dedicated computer, an IBM 4380.

Most importantly, the university library computer is linked to the mainframe of the university Computer Center. This enables users to retrieve data from the university library computer from over 800 terminals in the university. Departmental libraries are hooked up to the library system and input catalog information. The database of the library system, hence, is becoming the automated Union Catalog of the university.

The Heidelberg system, though a local, integrated system, is not an isolated one. Cataloging is done in the Regional Southwest Germany Library Network with its mainframe in Konstanz. To do this, new cataloging rules had to be introduced in 1986 - the so-called RAK ("Rules for Alphabetic Cataloging"), which unfortunately does not agree with AACR2 in many details. Moreover, the German Data Format, MAB (machine-readable exchange format for libraries) is not compatible with MARC either.

Librarians in Heidelberg nevertheless are adjusting the local system to the regional network. Thus, they are optimistic that they will be successful in using the data of large American databases in order to start the retrospective conversion of their collection of books before 1986. They matched a selection of some 100 catalog cards of their total holdings against the databases of OCLC and UTLAS, resulting in a $46 \%$ match. For parts of the catalog under the Prussian Rules, with titles published between 1936-1985, they found a hit rate of $86 \%$ with OCLC. They are preparing a contract with one of these utilities in order to convert this catalog of about 800,000 entries. Their extensive experience in converting data from national and regional services is enabling them to convert the American MARC data into their MAB format. They will have to assess the extent of the differences between AACR and RAK rules next.

Heidelberg University Library is looking forward to cooperating with American academic libraries for global information sharing.

Editor's Note: This article is based on a talk by the author at the Fifth ACRL National Conference in Cincinnati, April 7, 1989.

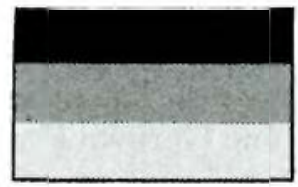




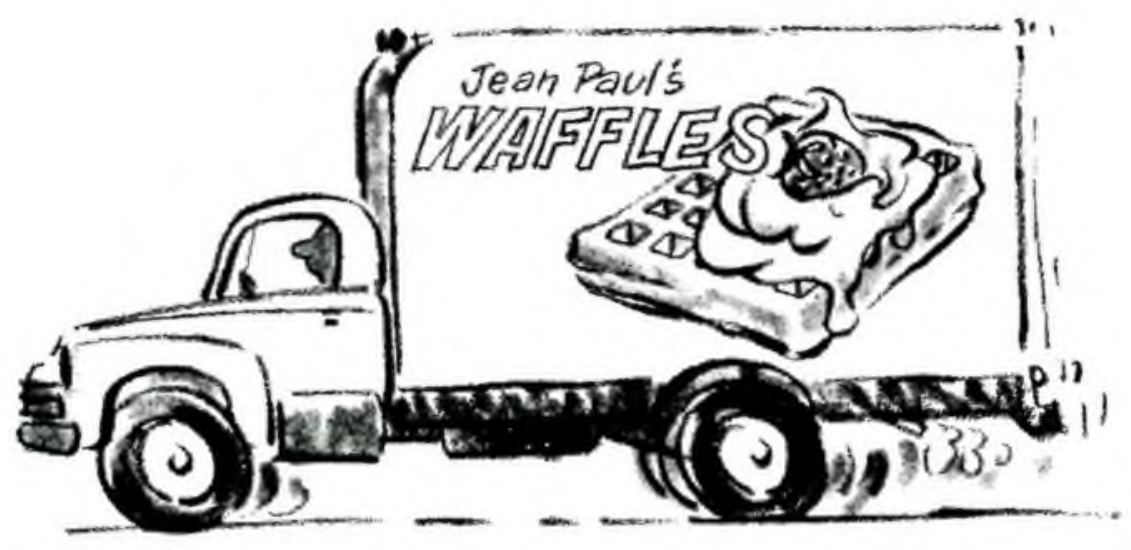

\section{Where can you find statistics on the weight, capacity, and fuel requirements of trucks in Belgium?}

Next time you face a tough question, next time you need an answer other print and electronic indexes can't provide, start your search where you're bound to find the right answer: PAIS. Only PAIS' acclaimed public/social policy indexes give you:

- Selective coverage of the public/social aspects of business, economics, finance, law and legislation, international trade and relations, public health, and much more.

- Eclectic coverage of literature published around the world in English, French, German, Italian, Portuguese, and Spanish.
- Precise indexing of monographs, periodicals, directories, government documents-in all, nearly 300,000 stringently edited items in the electronic formats and more than one million items in the print indexes.

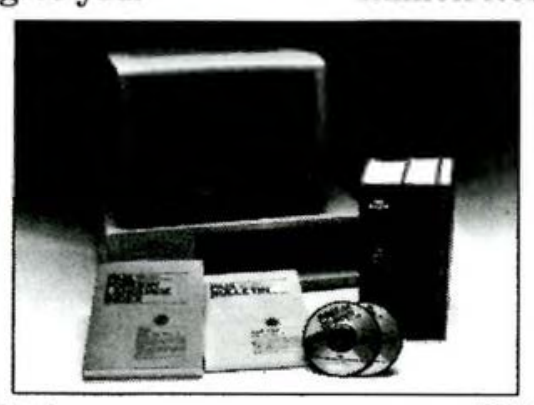

- A treasure trove of references to hard-to-find statistics, demographics, business trends, and background information.

- The indexing format that meets your needs best: print, online, or CD-ROM.

For more information on PAIS' family of public/social

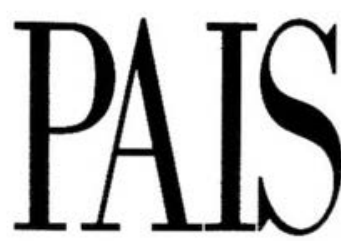
policy indexes, call today.

Public Affairs Information Service, Inc.

521 West 43 rd Street $•$ New York, NY 10036-4396 • 800-288-PAIS 212-736-6629 (outside the U.S.)

In Print: PAIS BULLETIN - PAIS FOREIGN LANGUAGE INDEX • PAIS SUBJECT HEADINGS

Online: PAIS INTERNATIONAL On Compact Disc: PAIS ON CD-ROM 


\section{Fast, effective relief for your acquisitions headaches.}

Unlike some CD-ROM products, which are nothing more than electronic vendors' catalogs, Books In Print Plus ${ }^{\mathrm{TM}}$ is an important acquisitions tool specifically designed to reduce the time and effort you spend on researching and ordering titles. Tasks that used to keep you and your staff busy for hours can now be completed in minutes.
Custom search through the database by combining any or all of up to 18 search criteria. For example, search for all titles dealing with wine published after 1987 and a list is displayed in seconds. If you then decide that French wines should be excluded from the search, make a simple command change and immediately all titles dealing with wine (with the exception of French wines) published after 1987 appear. The results are so incredible that once you try Books In Print Plus, it will change the way you do acquisitions forever.

\section{TAKE TWO MINUTES AND CALL} US IN THE MORNING.

To order Books In Print Plus for the IBM PC or Apple ${ }^{\oplus}$ Macintosh $^{\oplus}$, or for more information about how you can streamline your acquisitions process, call Bowker Electronic Publishing toll-free at 1-800-521-8110. In New York, Alaska, and Hawaii please call us collect at 212-337-6934. For technical assistance call 1 800-323-3288. You'll be feeling better in no time. time getting up and running with Books In Print Plus.

On-screen prompts, instant help screens, and a special novice mode insure that you won't waste any
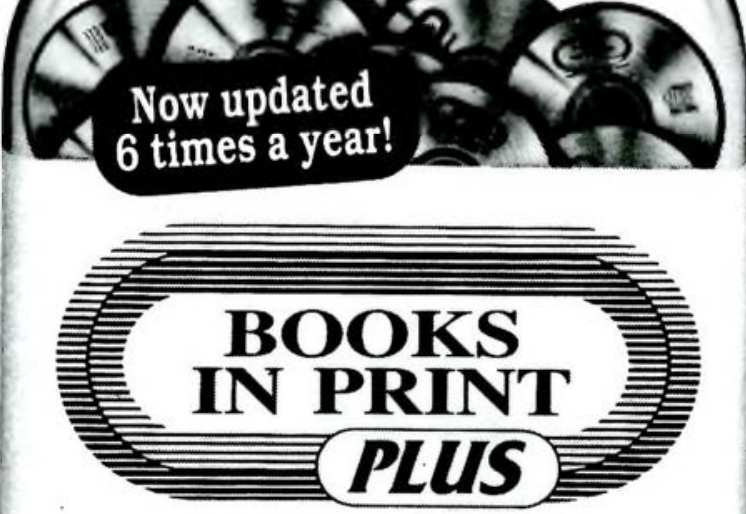

FAST, EFFECTIVE RELIEF FOR ACQUISITIONS HEADACHES.

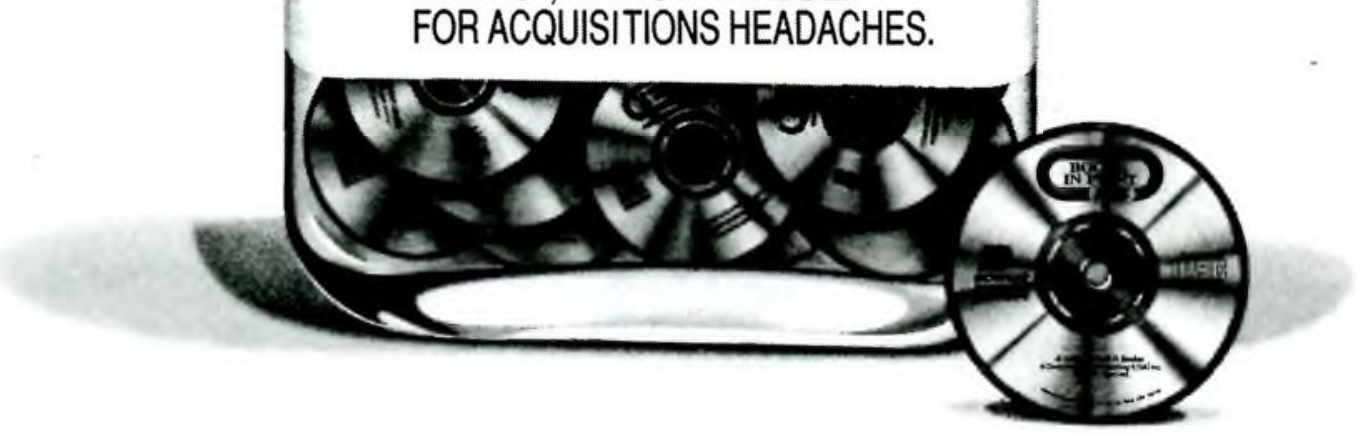

- Electronic ordering software furnished by distributors. 


\section{CD-ROM II Teleconference set for November}

The Association of College and Research Libraries, its Community and Junior College Libraries Section (CJCLS), and the Community College Association for Instruction and Technology (CCAIT) will co-sponsor CD-ROM II, a national teleconference featuring the development and advancements of CD-ROM technology, on Wednesday, November 15, 1989, from 11:00 a.m. to 12:30 p.m. CST, from the studios of the College of DuPage, Glen Ellyn, Illinois.

The teleconference is designed especially for information management specialists and library or LRC personnel with some CD-ROM familiarity. Scheduled events include:

- Practitioners' Forum: direct, first-hand experience of professionals from public, special, and academic libraries.

- Networking News: Presentations of new networking potentials including CD-ROM OPACs (Online Public Access Catalogs), licensing agreements, training and technical support, LANs (local area networks) and WANs (wide area networks).

- Future Developments: where the technology is headed and what it will be like for the information providers.

- Vendor Forum: A discussion of CD-ROM software and technology from the producers.

Questions from the viewing participants will be answered during each module.

Following the teleconference there will be a special feature, the CD-ROM Showcase, from 12:30-1:30 p.m. Vendors will present a 60 -minute showcase of current CD-ROM products as an optional event at no extra charge. Videotaping is encouraged.

Institutions may register as receive sites for $\$ 175$. The fee entitles the institution to videotaping rights, telephoning rights, $\mathrm{Ku}$ and $\mathrm{C}$-band reception, and three participant packets. Each packet will include copies of landmark articles, an evaluation form, an entry coupon for a free equipment and database drawing which will be held at the end of the program, and an overview discography. Additional packets are $\$ 10 \mathrm{each}$, minimum order of three.

Additional information on the teleconference, which is being produced under the auspices of the College of DuPage, may be obtained from Bernard Fradkin, Dean of the Learning Resources Center, College of DuPage, 22d Street and Lambert Road, Glen Ellyn, IL 60137-6599; (312) 858-6090.

\section{White House Conference set for July 1991}

The White House Conference on Library and Information Services (WHCLIS II) has been scheduled to be held in Washington, D.C.'s Convention Center from Tuesday, July 9, through Saturday, July 13, 1991. With state and territorial preconference activities expected to be held from May 1990 through April 1991, there will be time for recommendations developed at the state and territorial level to be processed for consideration at the Washington meeting.

The three overall conference themes are: library and information services for productivity, library and information services for literacy, and library and information services for democracy. The $\mathrm{Na}-$ tional Conference is expected to consider such topics as:

- how library and information services can provide business and industry (and especially small business) improved access to needed information;

- how to ensure access to new information technologies;

- how to meet the information and other needs of senior citizens, the disabled, the disadvantaged, the functionally illiterate, and those whose primary language is not English;

- how to use new technologies more effectively to serve learners;

- training and education programs in penal institutions;

- how to improve services through cooperation with the private sector;

- how to make use of technology to store, analyze and transmit information needed by the public and by government decision-makers; and

- how to help information users sift through an ever-expanding information supply, extracting what is useful, reliable and timely.

After the conference is concluded, a public report of its findings and recommendations will be submitted to the President and to Congress.

The conference was authorized by Public Law 100-382 and signed by President Reagan on August 8,1988 . Its purpose is "to develop recommendations for the further improvement of the library and 
information services of the Nation and their use by the public." The conference will be planned and conducted by the U.S. National Commission on Libraries and Information Science (NCLIS) with the assistance and advice of a 30-member White House Conference Advisory Committee (WHCAC) whose members represent all areas of the U.S.

NCLIS chairman Jerald C. Newman has written all state and territorial governors, informing them of the conference and urging them to submit applications for federal funds to help initiate preconference activities. Initial grants to the states will be shares of the $\$ 1.75$ million appropriated by Con- gress. As additional funds become available, states and territories may be eligible for other support for preconference activities.

Participants in the state and territorial programs and at the National Conference are to represent a broad spectrum of the population. The law provides that a fourth of the participants will be selected from the library and information profession; a fourth will be selected from trustees, friends groups, and other individuals who are active library and information supporters; a fourth will be selected from federal, state or local officials; and a fourth will be selected from the general public.

\section{Benefits received by college}

\section{librarians}

\author{
By John Robson
}

Library Director

Rose-Hulman Institute of Technology and Susan A. Stussy

Library Director

St. Norbert College

\section{A survey of 119 college libraries in the Midwest.}

A lthough ALA publishes annual salary surveys, no nationwide survey of the benefits received by college librarians now exists. We believe that benefit issues are particularly crucial for academic librarians due to the unclear social status and politically vulnerable position of many, if not most, librarians in higher education. Job classifications are a perennial problem for academic librarians, and they may admit an employee to the eligibility pool for significant institutional benefits or exclude that employee from consideration for institutional benefits granted only to individuals in more highly regarded job classifications. While recent legal changes have restricted the ability of employers to discriminate between classes of employees concerning access to crucial benefits such as health care and pension funding, discrimination still exists even in these key areas.

The ACRL College Libraries Section's Ad Hoc Committee on Real Income thoroughly considered the issue of the benefits received by academic librarians between 1985 and 1988. Susan A. Stussy chaired that committee, and John Robson was a member. Unfortunately, this committee was unable to accomplish a great deal due to the inexperience of both the members and the chair.

After the committee concluded its work, the authors resolved to find out where college librarians in the five states of Illinois, Indiana, Michigan, Ohio, and Wisconsin stood in terms of access to standard employee benefits and eligibility for academic benefits such as sabbaticals and tenure. 